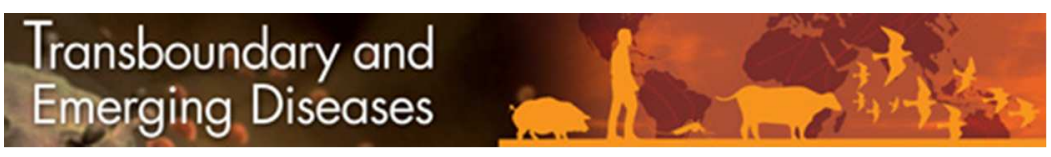

\title{
Concurrent infection of Bluetongue and Peste-des-petits- ruminants virus in small ruminants in Haryana state of India
}

\begin{tabular}{|c|c|}
\hline Journal: & Transboundary and Emerging Diseases \\
\hline Manuscript ID & TBED-SC-366-16.R1 \\
\hline Manuscript Type: & Short Communication \\
\hline Date Submitted by the Author: & $\mathrm{n} / \mathrm{a}$ \\
\hline Complete List of Authors: & $\begin{array}{l}\text { Maan, S; Lala Lajpat Rai University of Veterinary and Animal Sciences } \\
\text { (LUVAS), Animal Biotechnology } \\
\text { Kumar, Aman; Lala Lajpat Rai University of Veterinary and Animal Sciences } \\
\text { (LUVAS), Animal Biotechnology } \\
\text { Gupta, Akhil; Lala Lajpat Rai University of Veterinary and Animal Sciences } \\
\text { (LUVAS), Department of Veterinary Microbiology } \\
\text { Dalal, Anita; Lala Lajpat Rai University of Veterinary and Animal Sciences } \\
\text { (LUVAS), Animal Biotechnology; Department of Veterinary Microbiology } \\
\text { Chaudhary, Deepika ; Lala Lajpat Rai University of Veterinary and Animal } \\
\text { Sciences (LUVAS), Animal Biotechnology } \\
\text { Gupta, Tarun; Lala Lajpat Rai University of Veterinary and Animal Sciences } \\
\text { (LUVAS), Teaching Veterinary Clinical Complex } \\
\text { Kumar, Nitish; Lala Lajpat Rai University of Veterinary and Animal Sciences } \\
\text { (LUVAS), , Animal Biotechnology } \\
\text { kumar, vinay; Lala Lajpat Rai University of Veterinary and Animal Sciences } \\
\text { (LUVAS), Animal Biotechnology; } \\
\text { Batra, Kanisht; Lala Lajpat Rai University of Veterinary and Animal } \\
\text { Sciences (LUVAS), , Animal Biotechnology } \\
\text { Sindhu, Neelesh; Lala Lajpat Rai University of Veterinary and Animal } \\
\text { Sciences (LUVAS), , Teaching Veterinary Clinical Complex } \\
\text { Kumar, Ankit; Lala Lajpat Rai University of Veterinary and Animal Sciences } \\
\text { (LUVAS) } \\
\text { Mahajan, Nand; Lala Lajpat Rai University of Veterinary and Animal } \\
\text { Sciences (LUVAS), Veterinary Public Health \& Epidemiology } \\
\text { Maan, N.S.; Lala Lajpat Rai University of Veterinary and Animal Sciences } \\
\text { (LUVAS), , Department of Animal Nutrition and Resource faculty, } \\
\text { Department of Animal Biotechnology } \\
\text { Mertens, Peter; The Pirbright institute, Vector-borne disease proramme }\end{array}$ \\
\hline Subject Area: & $\begin{array}{l}\text { Arboviruses, Diagnostics, Disease control, Emerging diseases, Veterinary } \\
\text { epidemiology, Trade/Effects on trade, Transmission, Vaccine }\end{array}$ \\
\hline
\end{tabular}

\section{SCHOLARONE ${ }^{\text {Th }}$ \\ Manuscripts}




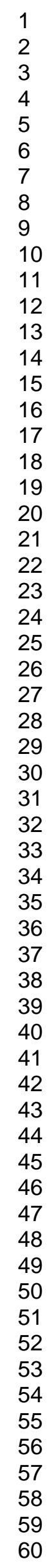
60 
Concurrent infection of Bluetongue and Peste-des-petits-ruminants virus in small ruminants in Haryana state of India

3

4 Sushila Maan ${ }^{1}$, Aman Kumar ${ }^{1}$, Akhil Kumar Gupta ${ }^{2}$, Anita Dalal ${ }^{1,2}$, Deepika Chaudhary ${ }^{1}$, Tarun

5 Kumar Gupta $^{3}$, Nitish Bansal ${ }^{1}$, Vinay Kumar ${ }^{1}$, Kanisht Batra ${ }^{1}$, Neelesh Sindhu ${ }^{3}$, Ankit Kumar ${ }^{4}$,

6 Nand K. Mahajan ${ }^{5}$, Narender Singh Maan ${ }^{6}$ and Peter P.C. Mertens ${ }^{7,8}$

7

$8{ }^{1}$ Department of Animal Biotechnology, College of Veterinary Sciences, Lala Lajpat Rai 9 University of Veterinary and Animal Sciences, Hisar, 125 004, Haryana, India.

$10{ }^{2}$ Department of Veterinary Microbiology, College of Veterinary Sciences, Lala Lajpat Rai 11 University of Veterinary and Animal Sciences, Hisar, 125 004, Haryana, India.

$12{ }^{3}$ Teaching Veterinary Clinical Complex, College of Veterinary Sciences, Lala Lajpat Rai 13 University of Veterinary and Animal Sciences, Hisar, 125 004, Haryana, India.

$14{ }^{4}$ TVCC Regional Centre, Uchani (Karnal), College of Veterinary Sciences, Lala Lajpat Rai 15 University of Veterinary and Animal Sciences, Hisar, 125 004, Haryana, India.

$16{ }^{5}$ Veterinary Public Health \& Epidemiology, College of Veterinary Sciences, Lala Lajpat Rai 17 University of Veterinary and Animal Sciences, Hisar- 125004.

$18{ }^{6}$ Department of Animal Nutrition and Resource faculty, Department of Animal Biotechnology, 19 College of Veterinary Sciences, Lala Lajpat Rai University of Veterinary and Animal Sciences, 20 Hisar- 125004.

$21{ }^{7}$ The Pirbright Institute, Pirbright, Surrey, United Kingdom, UK.

$22{ }^{8}$ School of Veterinary Medicine and Science, University of Nottingham, Sutton Bonington 23 Campus, Leicestershire, United Kingdom.

$24 *$ Corresponding author:

25 Dr, Sushila Maan, Principal Scientist, Department of Animal Biotechnology, College of

26 Veterinary Sciences, LLR University ofVeterinary and Animal Sciences, Hisar, Haryana, India

27 E mail: sushilamaan105@gmail.com; sushilamaan105@luvas.edu.in

28

\section{Running title: Co-infection of BTV and PPRV in Haryana, India}

30 Keywords:

31 Bluetongue, Peste-des-petits-ruminants virus, Haryana, India, Epidemiology. 


\section{Summary}

33 Bluetongue (BT) and Peste-des-petits-ruminants (PPR), are major transboundary diseases of small ruminant, which are endemic in India. Testing of bluetongue virus (BTV) and peste-despetits-ruminants virus (PPRV), from recent outbreaks (2015-2016) in different regions of Haryana state of India revealed that $27.5 \%$ of the samples showed the presence of dual infection

of BTV and PPRV. Analysis of Seg-2 of BTV (the serotype determining protein) showed the presence of BTV-12w in several isolates. However, analysis of $\mathrm{N}$ gene fragment amplicons showed that viruses belong to lineage IV most closely related to a pathogenic strain of PPRV from Delhi. This is the first report of co-circulation of PPRV lineage IV and bluetongue virus serotype 12 in the state.

\section{Contents}

Haryana is one of the 29 states in India, situated in North and its Livestock population consist of 6.08 million buffalos, 1.80 million cattle, 0.36 million sheep, and 0.36 million goats which represents the main livelihood for the majority of the rural population of Haryana...

Bluetongue (BT) is an arthropod-transmitted, WOAH notifiable, viral disease of ruminants and certain other animals. Bluetongue virus (BTV) is the 'type species' of the genus Orbivirus within the Reoviridae family (Mertens et al., 2005). Twenty-seven serotypes have been recognized for this virus so far (Hofmann et al., 2008, Maan et al., 2011, Zientara et al., 2014). There is evidence of two additional putative serotypes (Maan et al., 2016).The BTV genome consists of ten segments of double-stranded RNA surrounded by three concentric protein layers without any lipid envelope (Mertens et al., 2009).

In India several BTV serotypes $-1 \mathrm{e},-2 \mathrm{e},-2 \mathrm{w}-3 \mathrm{e},-5 \mathrm{w},-9 \mathrm{e},-10 \mathrm{w},-12 \mathrm{w},-16 \mathrm{e},-21 \mathrm{e}$ $-23 \mathrm{e}$ and $-24 \mathrm{w}$ are currently circulating (Maan et al., 2015b, Rao et al., 2014). Only two BTV serotypes (BTV-1 and BTV-4) have been previously isolated from Haryana state in 1985 (Jain et al., 1986) and in 2001 (Uppal and and Vasudevan, 1980). However, there is serological evidence of BTV-2, -8, -12 and -16 from Haryana (Prasad et al., 2009).

Similarly Peste-des-petits-ruminants is another serious, highly contagious, WOAH notifiable and economically important transboundary infectious disease of sheep and goats, which is associated with high mortality and morbidity. Although, a live attenuated PPR vaccine based on the PPRV/Sungri/96 strain is being used in India even then, PPR outbreaks are being 
63 reported in small ruminants recurrently throughout the year (Balamurugan et al., 2012, Kumar et 64 al., 2014).

This disease is caused by peste-des-petits-ruminants virus (PPRV), which belongs to the genus Morbillivirus of the family Paramyxoviridae (sub family Paramyxovirinae) under the 67 order Mononegavirales (Lefevre and Diallo, 1990). The PPRV genome encodes six structural 68 (N, P, M, F, H and L) and two nonstructural (C and V) proteins (Mahapatra et al., 2006). The 69 PPRV is genetically grouped into four lineages (I, II, III, and IV) based on the partial F and N 70 gene sequences analyses. Lineages I-III have been found to circulate in Africa, while lineage IV 71 is generally reported from Asia (Banyard et al., 2010, Kwiatek et al., 2011). However, over the 72 last decade, there have been reports of the presence of the Asian lineage of PPRV in several 73 African countries (Kwiatek et al., 2011, De Nardi et al., 2012).

74 Spread of both PPR and BT diseases to a number of new geographical areas with 75 involvement of various lineage of PPRV and multiple topotypes and serotypes of BTV is a cause 76 of global concern, thus prompting us to reassess the epidemiological situation of BTV and PPRV 77 in Haryana.

78 During this study, a total of 348 clinical samples (240 from sheep and 108 from goats) 79 consisting of various tissues (spleen, trachea, lung, liver and lymph nodes), blood, nasal, ocular 80 and rectal swabs were collected from different villages of Haryana between 2015 and 2016 from the outbreaks of PPR and/or BT that occurred throughout the year irrespective of the season 82 (data from March 2015 to July 2016). This could be because the winters were very mild and also 83 summers were not that harsh during the period under study. Both sheep and goat showed similar 84 disease pattern and the clinical signs in the affected animals included high rise of temperature 85 $\left(105^{0} \mathrm{~F}-106^{0} \mathrm{~F}\right)$, depression, anorexia, hyperemia of mucus membranes of lips and nostrils, 87 animals were between 3 and 12 months of age. Goats and sheep were kept together in these areas 88 where they shared grazing land and drinking water sources. The samples were collected from 89 migratory flocks and from the flocks kept by local farmers involving native breeds of sheep (Nali 90 and Munjal) and goats (Beetal). The location of each sample was recorded using the standard 91 proforma devised for the Orbivirus reference collection (ORC) at the Pirbright Laboratory, UK 92 (http://www.reoviridae.org/dsRNA_virus_proteins/ReoID/btv-1.htm). 
Total RNA was extracted from the samples (nasal/ocular/rectal cotton swabs/tissues/ cell culture supernatants) either using a QIAamp Viral RNA Mini Kit (Qiagen, Hilden, Germany) according to the manufacturers' instructions or using Trizol Reagent (Life Technologies Inc) (Attoui et al., 2000). Additionally, RNA from uninfected tissue culture supernatants and uninfected sheep and goat blood was also extracted for use as negative controls.

These samples were analysed for the presence of BTV RNA and PPRV RNA using Seg-9 (Maan et al., 2015a) and Seg-10 (Orru et al., 2006) specific and N gene specific qRT-PCR assays respectively (Batten et al., 2011). 253 samples (72.70\%) were positive for the presence of BTV and 137 samples (39.36 \%) for PPRV. In 96 (27.5\%) of cases there were dual infection of BTV and PPRV.

The samples with $\mathrm{Ct}$ values less than 30 were taken further for virus isolations in respective cell lines. Majority of the samples that were positive for BTV were converted into isolates in KC and BHK cells. BTV isolates (e.g. IND2015/340 originating from field sample IND2015/338) produced characteristic CPE in BHK-21 cells (granulation, rounding, detachment and degeneration of cells). Some of the selective samples showing concurrent infection of BTV and PPRV were passaged directly in Vero SLAM cells, as previously described (Chinnakannan et al., 2013) for isolation of PPRV. PPRV isolates generated (e.g. PPRV/IND2015/02 originating from same field sample IND2015/338) also produced characteristic CPE in Vero SLAM cells, which was characterised by rounding and ballooning of cells followed by aggregation of cells and formation of fusion mass and syncytia. Cell lysis was also observed in some cases.

The BTV isolates were serotyped using qRT-PCR assays either using a panel of type specific qRT-PCR assays targeting Seg-2 (Maan et al., 2016), which revealed the presence of BTV-12 in all of isolates from different regions of Haryana showing concurrent infection of BTV and PPRV. Conventional gel based Seg-2 specific type assays confirmed the presence of BTV-12w in the isolates that were tested (Maan et al., 2012).

Seg-2 of BTV-12 isolates was amplified in four overlapping fragments using the primers listed in table 1. Sequencing of these Seg-2 amplicons on ABI capillary sequencer 3130 using a 'Big dye cycle sequencing kit' followed by assembly using Lasergene software ver. 5.0, has confirmed the presence of serotypes 12 in these isolates. Comparison of full length BTV-12 Seg2 nucleotide sequences (from isolate IND2015/340 - accession no KX905151) and partial sequences from the other BTV-12 isolates (not listed here) in MEGA software version 6 (Tamura 
124 et al., 2013), showed that these were very closely related to each other (99.9\% nt identity) and to 125 another Indian isolate from southern India BTV-12/INDAPADBNMO1/11 (Accession no. 126 KC662613) (99.3\%)(Rao et al., 2013) (Figure 1). Seg-2 of IND2015/340 showed 97.1\% nt

127 sequence identity with the reference strain of BTV-12 from South Africa (Accession no. 128 AJ585133) and Kenya (Accession no. AJ585185), and share 95.8\% to 96.6\% nt sequence 129 identity to strains from Taiwan (Accession nos. GU390659 and AB686216). On the contrary, 130 Seg-2 of IND2015/340 showed greater variation (87.6\% nt identity) from BTV-12 strain from 131 France Guyane (Accession no. KC633278).

132 Sequencing of partial $\mathrm{N}$ gene amplicons (generated using the primers listed in table 1) 133 from PPRV samples and isolates has confirmed the results of real time RT-PCR assays for the 134 presence of PPRV RNA. Partial N gene based phylogeny (1576 bp of PPRV/IND2015/02 135 [accession no - KX905152]), revealed that most of the PPRV strains collected from Haryana 136 between 2015 and $2016(\mathrm{n}=137)$ grouped together in lineage IV very closely related with other 137 strains from India (IND/Delhi/2016/05 - Accession no. KX033350, IND/TN/GIN/2014/01 138 Accession no. KT270355 and India/TN/Gingee/2014 - Accession no. KR261605) with 98.4\% to $13998.9 \%$ nt identity in $\mathrm{N}$ gene supported by a bootstrap value of $>90 \%$ (Figure 2 ). However, the $140 \%$ nt identity in $\mathrm{N}$ gene with the vaccine strain being used in India (Sungri 1996 MSD 141 Accession no. - KJ867542) is 96.8\%. The phylogeny inferred for BTV Seg-2 and PPRV N gene 142 with the distance methods were consistent with those of the character-based analysis.

143 The findings of this study relating to BT and PPR surveillance in Haryana over a more 144 than one year period (January 2015 - July 2016) have confirmed the widespread distribution of 145 BT and PPRV throughout the province. The concurrent infection of BTV and PPRV has been 146 reported in Haryana. This is the first report of circulation of PPRV lineage IV and bluetongue 147 virus serotype 12 in the state.

148

\section{Acknowledgements}

150 The authors would like to acknowledge funding support from BBSRC-DBT (BB/L004690/1; 151 BT/IN/Indo-UK/FADH/46/SM/2013), DBT Bio-CARe grant (BT/Bio-CARe/04/261/2011-12), 152 and Rashtriya Krishi Vikas Yojana (RKVY) from Govt. of India. Sushila Maan is a DBT Bio153 CARe scientist. The authors would also like to thank all collaborators of BBSRC-DBT project 154 and various staff of Animal Husbandry Department of Haryana for their direct or indirect help. 
155

156 The authors declare no conflict of interest.

157 Tables:

158 Table 1. Details of primers used for amplification of $\mathrm{N}$ gene of Peste-des-petits-ruminants virus 159 (PPRV) and VP2 gene of Bluetongue virus (BTV) for use in RT-PCR assays.

160

161

162

163

164

165

166

167

168

169

170

171

172

173

174

175

176

177

178

179

180

181

182

183

184

185

186

187

188

\section{Figure legends}

Figure 1: Neighbour-joining tree showing the relationships between Seg-2 of IND2015/340 with the twenty nine reference strains of different BTV serotypes. The tree was constructed using distance matrices, generated using the p-distance determination algorithm in MEGA 6.0 (500 bootstrap replicates). The bootstrap values are indicated at the evolutionary branching points. The tree based on the character based method (Maximum likelihood) showed very similar topology.

Figure 2: Neighbour-joining tree showing the relationships between $\mathbf{N}$ gene sequence of PPRV/IND2015/338 with the other global strains of Morbiliviruses. The tree was constructed with partial (1576 bp) N gene sequences, using the p-distance determination algorithm in MEGA 6.0 (500 bootstrap replicates). The bootstrap values are indicated at the evolutionary branching points. The tree based on the character based method (Maximum likelihood) showed very similar topology.

\section{References:}

Attoui, H., F. Billoir, J. F. Cantaloube, P. Biagini, P. de Micco and X. de Lamballerie, 2000: Strategies for the sequence determination of viral dsRNA genomes. J Virol Methods, 89, 147-158.

Balamurugan, V., A. Sen, G. Venkatesan, V. Bhanot, V. Yadav, V. Bhanuprakash and R. K. Singh, 2012: Peste des petits ruminants virus detected in tissues from an Asiatic lion (Panthera leo persica) belongs to Asian lineage IV. J Vet Sci, 13, 203-206.

Banyard, A. C., S. Parida, C. Batten, C. Oura, O. Kwiatek and G. Libeau, 2010: Global distribution of peste des petits ruminants virus and prospects for improved diagnosis and control. J Gen Virol, 91, 2885-2897.

Batten, C. A., A. C. Banyard, D. P. King, M. R. Henstock, L. Edwards, A. Sanders, H. Buczkowski, C. C. Oura and T. Barrett, 2011: A real time RT-PCR assay for the specific detection of Peste des petits ruminants virus. J Virol Methods, 171, 401-404.

Chinnakannan, S. K., S. K. Nanda and M. D. Baron, 2013: Morbillivirus v proteins exhibit multiple mechanisms to block type 1 and type 2 interferon signalling pathways. PLoS One, 8, e57063. 
De Nardi, M., S. M. Lamin Saleh, C. Batten, C. Oura, A. Di Nardo and D. Rossi, 2012: First evidence of peste des petits ruminants (PPR) virus circulation in Algeria (Sahrawi territories): outbreak investigation and virus lineage identification. Transbound Emerg Dis, 59, 214-222.

Hofmann, M., C. Griot, V. Chaignat, L. Perler and B. Thur, 2008: [Bluetongue disease reaches Switzerland]. Schweiz Arch Tierheilkd, 150, 49-56.

Jain, N. C., R. Sharma and G. Prasad, 1986: Isolation of bluetongue virus from sheep in India. Vet Rec, 119, 17-18.

Kumar, N., S. Maherchandani, S. K. Kashyap, S. V. Singh, S. Sharma, K. K. Chaubey and H. Ly, 2014: Peste des petits ruminants virus infection of small ruminants: a comprehensive review. Viruses, 6, 2287-2327.

Kwiatek, O., Y. H. Ali, I. K. Saeed, A. I. Khalafalla, O. I. Mohamed, A. A. Obeida, M. B. Abdelrahman, H. M. Osman, K. M. Taha, Z. Abbas, M. El Harrak, Y. Lhor, A. Diallo, R. Lancelot, E. Albina and G. Libeau, 2011: Asian lineage of peste des petits ruminants virus, Africa. Emerg Infect Dis, 17, 1223-1231.

Lefevre, P. C. and A. Diallo, 1990: Peste des petits ruminants. Rev Sci Tech, 9, 935-981.

Maan, N. S., S. Maan, M. Belaganahalli, G. Pullinger, A. J. Montes, M. R. Gasparini, M. Guimera, K. Nomikou and P. P. Mertens, 2015a: A quantitative real-time reverse transcription PCR (qRT-PCR) assay to detect genome segment 9 of all 26 bluetongue virus serotypes. J Virol Methods, 213, 118-126.

Maan, N. S., S. Maan, M. N. Belaganahalli, E. N. Ostlund, D. J. Johnson, K. Nomikou and P. P. Mertens, 2012: Identification and differentiation of the twenty six bluetongue virus serotypes by RT-PCR amplification of the serotype-specific genome segment 2. PLoS One, 7, e32601.

Maan, S., N. S. Maan, M. N. Belaganahalli, A. C. Potgieter, V. Kumar, K. Batra, I. M. Wright, P. D. Kirkland and P. P. Mertens, 2016: Development and Evaluation of Real Time RT-PCR Assays for Detection and Typing of Bluetongue Virus. PLoS One, 11, e0163014.

Maan, S., N. S. Maan, M. N. Belaganahalli, P. P. Rao, K. P. Singh, D. Hemadri, K. Putty, A. Kumar, K. Batra, Y. Krishnajyothi, B. S. Chandel, G. H. Reddy, K. Nomikou, Y. N. Reddy, H. Attoui, N. R. Hegde and P. P. Mertens, 2015b: Full-Genome Sequencing as a Basis for Molecular Epidemiology Studies of Bluetongue Virus in India. PLoS One, 10, e0131257.

Maan, S., N. S. Maan, K. Nomikou, C. Batten, F. Antony, M. N. Belaganahalli, A. M. Samy, A. A. Reda, S. A. Al-Rashid, M. El Batel, C. A. Oura and P. P. Mertens, 2011: Novel bluetongue virus serotype from kuwait. Emerg Infect Dis, 17, 886-889.

Mahapatra, M., S. Parida, M. D. Baron and T. Barrett, 2006: Matrix protein and glycoproteins F and H of Peste-des-petits-ruminants virus function better as a homologous complex. J Gen Virol, 87, 2021-2029.

Mertens, P. P. C., S. Maan, A. Samuel and H. Attoui, 2005: Orbiviruses, Reoviridae. In: C. M. Fauquet, M.A. Mayo, J. Maniloff, U. Desselberger and L.A. Ball (ed), Virus Taxonomy. Eighth Report of the International Committee on Taxonomy of Viruses, pp. 466-483. Elsevier/Academic Press, London.

Mertens, P. P. C., N. Ross-smith, J. Diprose and H. Attoui, 2009: The structure of bluetongue virus core and proteins. In: P. S. Mellor, M. Baylis and P. P. C. Mertens (eds), Bluetongue, Ist edn., pp. 101125. Elsevier/Academic Press London

Orru, G., M. L. Ferrando, M. Meloni, M. Liciardi, G. Savini and P. De Santis, 2006: Rapid detection and quantitation of Bluetongue virus (BTV) using a Molecular Beacon fluorescent probe assay. $J$ Virol Methods, 137, 34-42.

Prasad, G., D. Sreenivasulu, K. P. Singh, P. P. C. Mertens and S. Maan, 2009: Bluetongue in the Indian subcontinent. In: P. S. Mellor, M. Baylis and P. P. C. Mertens (eds), Bluetongue, Ist edn., pp. 167196. Elsevier/Academic Press London 
1

2

3

4

5

6

7

8

9

10

Rao, P. P., N. R. Hegde, Y. N. Reddy, Y. Krishnajyothi, Y. V. Reddy, B. Susmitha, S. R. Gollapalli, K. Putty and G. H. Reddy, 2014: Epidemiology of Bluetongue in India. Transbound Emerg Dis.

236

Rao, P. P., Y. V. Reddy and N. R. Hegde, 2013: Isolation and Complete Genome Sequencing of Bluetongue Virus Serotype 12 from India. Transbound Emerg Dis.

Tamura, K., G. Stecher, D. Peterson, A. Filipski and S. Kumar, 2013: MEGA6: Molecular Evolutionary Genetics Analysis version 6.0. Mol Biol Evol, 30, 2725-2729.

Uppal, P. K. and B. and Vasudevan, 1980: Occurrence of bluetongue in India. Indian. J. Comp. Microbiol. Immunol. Infect. Dis., 1, 18-20.

Zientara, S., C. Sailleau, C. Viarouge, D. Hoper, M. Beer, M. Jenckel, B. Hoffmann, A. Romey, L. BakkaliKassimi, A. Fablet, D. Vitour and E. Breard, 2014: Novel bluetongue virus in goats, corsica, france, 2014. Emerg Infect Dis, 20, 2123-2132. 
1 Concurrent infection of Bluetongue and Peste-des-petits-ruminants virus in small

3

4 Sushila Maan ${ }^{1}$, Aman Kumar ${ }^{1}$, Akhil Kumar Gupta ${ }^{2}$, Anita Dalal ${ }^{1,2}$, Deepika Chaudhary ${ }^{1}$, Tarun

5 Kumar Gupta $^{3}$, Nitish Bansal ${ }^{1}$, Vinay Kumar ${ }^{1}$, Kanisht Batra ${ }^{1}$, Neelesh Sindhu ${ }^{3}$, Ankit Kumar ${ }^{4}$,

6 Nand K. Mahajan ${ }^{5}$, Narender Singh Maan ${ }^{6}$ and Peter P.C. Mertens ${ }^{7,8}$

7

${ }^{1}$ Department of Animal Biotechnology, College of Veterinary Sciences, Lala Lajpat Rai University of Veterinary and Animal Sciences, Hisar, 125 004, Haryana, India.

${ }^{2}$ Department of Veterinary Microbiology, College of Veterinary Sciences, Lala Lajpat Rai University of Veterinary and Animal Sciences, Hisar, 125 004, Haryana, India.

${ }^{3}$ Teaching Veterinary Clinical Complex, College of Veterinary Sciences, Lala Lajpat Rai University of Veterinary and Animal Sciences, Hisar, 125 004, Haryana, India.

${ }^{4}$ TVCC Regional Centre, Uchani (Karnal), College of Veterinary Sciences, Lala Lajpat Rai University of Veterinary and Animal Sciences, Hisar, 125 004, Haryana, India.

${ }^{5}$ Veterinary Public Health \& Epidemiology, College of Veterinary Sciences, Lala Lajpat Rai University of Veterinary and Animal Sciences, Hisar- 125004.

${ }^{6}$ Department of Animal Nutrition and Resource faculty, Department of Animal Biotechnology, College of Veterinary Sciences, Lala Lajpat Rai University of Veterinary and Animal Sciences, Hisar- 125004.

${ }^{7}$ The Pirbright Institute, Pirbright, Surrey, United Kingdom, UK.

${ }^{8}$ School of Veterinary Medicine and Science, University of Nottingham, Sutton Bonington Campus, Leicestershire, United Kingdom.

*Corresponding author:

Dr, Sushila Maan, Principal Scientist, Department of Animal Biotechnology, College of

Veterinary Sciences, LLR University ofVeterinary and Animal Sciences, Hisar, Haryana, India

Email: sushilamaan105@gmail.com; sushilamaan105@luvas.edu.in

\section{Running title: Co-infection of BTV and PPRV in Haryana, India}

Keywords:

Bluetongue, Peste-des-petits-ruminants virus, Haryana, India, Epidemiology. 


\section{Summary}

33 Bluetongue (BT) and Peste-des-petits-ruminants (PPR), are major transboundary diseases of small ruminant, which are endemic in India. Testing of bluetongue virus (BTV) and peste-despetits-ruminants virus (PPRV), from recent outbreaks (2015-2016) in different regions of Haryana state of India revealed that $27.5 \%$ of the samples showed the presence of dual infection of BTV and PPRV. Analysis of Seg-2 of BTV (the serotype determining protein) showed the presence of BTV-12w in several isolates. However, analysis of $\mathrm{N}$ gene fragment amplicons showed that viruses belong to lineage IV most closely related to a pathogenic strain of PPRV from Delhi. This is the first report of co-circulation of PPRV lineage IV and bluetongue virus serotype 12 in the state.

\section{Contents}

Haryana is one of the 29 states in India, situated in North and its Livestock population consist of 6.08 million buffalos, 1.80 million cattle, 0.36 million sheep, and 0.36 million goats which represents the main livelihood for the majority of the rural population of Haryana...

Bluetongue (BT) is an arthropod-transmitted, WOAH notifiable, viral disease of ruminants and certain other animals. Bluetongue virus (BTV) is the 'type species' of the genus Orbivirus within the Reoviridae family (Mertens et al., 2005). Twenty-seven serotypes have been recognized for this virus so far (Hofmann et al., 2008, Maan et al., 2011, Zientara et al., 2014). There is evidence of two additional putative serotypes (Maan et al., 2016). The BTV genome consists of ten segments of double-stranded RNA surrounded by three concentric protein layers without any lipid envelope (Mertens et al., 2009).

In India several BTV serotypes $-1 \mathrm{e},-2 \mathrm{e},-2 \mathrm{w}-3 \mathrm{e},-5 \mathrm{w},-9 \mathrm{e},-10 \mathrm{w},-12 \mathrm{w},-16 \mathrm{e},-21 \mathrm{e}$ $-23 \mathrm{e}$ and $-24 \mathrm{w}$ are currently circulating (Maan et al., 2015b, Rao et al., 2014). Only two BTV serotypes (BTV-1 and BTV-4) have been previously isolated from Haryana state in 1985 (Jain et al., 1986) and in 2001 (Uppal and and Vasudevan, 1980). However, there is serological evidence of BTV-2, -8, -12 and -16 from Haryana (Prasad et al., 2009).

Similarly Peste-des-petits-ruminants is another serious, highly contagious, WOAH notifiable and economically important transboundary infectious disease of sheep and goats, which is associated with high mortality and morbidity. Although, a live attenuated PPR vaccine based on the PPRV/Sungri/96 strain is being used in India even then, PPR outbreaks are being 
reported in small ruminants recurrently throughout the year (Balamurugan et al., 2012, Kumar et

al., 2014).

This disease is caused by peste-des-petits-ruminants virus (PPRV), which belongs to the genus Morbillivirus of the family Paramyxoviridae (sub family Paramyxovirinae) under the order Mononegavirales (Lefevre and Diallo, 1990). The PPRV genome encodes six structural (N, P, M, F, H and L) and two nonstructural (C and V) proteins (Mahapatra et al., 2006). The PPRV is genetically grouped into four lineages (I, II, III, and IV) based on the partial F and N gene sequences analyses. Lineages I-III have been found to circulate in Africa, while lineage IV is generally reported from Asia (Banyard et al., 2010, Kwiatek et al., 2011). However, over the last decade, there have been reports of the presence of the Asian lineage of PPRV in several African countries (Kwiatek et al., 2011, De Nardi et al., 2012).

Spread of both PPR and BT diseases to a number of new geographical areas with involvement of various lineage of PPRV and multiple topotypes and serotypes of BTV is a cause of global concern, thus prompting us to reassess the epidemiological situation of BTV and PPRV in Haryana.

During this study, a total of 348 clinical samples (240 from sheep and 108 from goats) consisting of various tissues (spleen, trachea, lung, liver and lymph nodes), blood, nasal, ocular and rectal swabs were collected from different villages of Haryana between 2015 and 2016 from the outbreaks of PPR and/or BT that occurred throughout the year irrespective of the season (data from March 2015 to July 2016). This could be because the winters were very mild and also summers were not that harsh during the period under study. Both sheep and goat showed similar disease pattern and The clinical signs in the affected animals included high rise of temperature $\left(105^{0} \mathrm{~F}-106^{0} \mathrm{~F}\right)$, depression, anorexia, hyperemia of mucus membranes of lips and nostrils, purulent nasal discharge, dermatitis, wool break, diarrhea and lameness. Most of the affected animals were between 3 and 12 months of age. Goats and sheep were kept together in these areas where they shared grazing land grazed together and shared the same drinking water sources. The samples were collected from migratory flocks and from the flocks kept by local farmers involving native breeds of sheep (Nali and Munjal) and goats (Beetal). The location of each 91 sample was recorded using the standard proforma devised for the Orbivirus reference collection 92 (ORC) at the Pirbright Laboratory, UK 93 (http://www.reoviridae.org/dsRNA virus proteins/ReoID/btv-1.htm). 
Total RNA was extracted from the samples (nasal/ocular/rectal cotton swabs/tissues/ cell culture supernatants) either using a QIAamp Viral RNA Mini Kit (Qiagen, Hilden, Germany) according to the manufacturers' instructions or using Trizol Reagent (Life Technologies Inc) (Attoui et al., 2000). Additionally, RNA from uninfected tissue culture supernatants and uninfected sheep and goat blood was also extracted for use as negative controls.

These samples were analysed for the presence of BTV RNA and PPRV RNA using Seg-9 (Maan et al., 2015a) and Seg-10 (Orru et al., 2006) specific and N gene specific qRT-PCR assays respectively (Batten et al., 2011). 253 samples (72.70\%) were positive for the presence of BTV and 137 samples (39.36 \%) for PPRV. In 96 (27.5\%) of cases there were dual infection of BTV and PPRV.

The samples with $\mathrm{Ct}$ values less than 30 were taken further for virus isolations in respective cell lines. Majority of the samples that were positive for BTV were converted into isolates in KC and BHK cells. BTV isolates (e.g. IND2015/340 originating from field sample IND2015/338) produced characteristic CPE in BHK-21 cells (granulation, rounding, detachment and degeneration of cells). Some of the selective samples showing concurrent infection of BTV and PPRV were passaged directly in Vero SLAM cells, as previously described (Chinnakannan et al., 2013) for isolation of PPRV. PPRV isolates generated (e.g. PPRV/IND2015/02 originating from same field sample IND2015/338) also produced characteristic CPE in Vero SLAM cells, which was characterised by rounding and ballooning of cells followed by aggregation of cells and formation of fusion mass and syncytia. Cell lysis was also observed in some cases.

The BTV isolates were serotyped using qRT-PCR assays either using BTV typing kits available from LSI (now Life Technologies Inc) or-a panel of type specific qRT-PCR assays targeting Seg-2 (Maan et al., 2016), which revealed the presence of BTV-12 in all of isolates from different regions of Haryana showing concurrent infection of BTV and PPRV. Conventional gel based Seg-2 specific type assays confirmed the presence of BTV-12w in the isolates that were tested (Maan et al., 2012).

Seg-2 of BTV-12 isolates was amplified in four overlapping fragments using the primers listed in table 1. Sequencing of these Seg-2 amplicons on ABI capillary sequencer 3130 using a 'Big dye cycle sequencing kit' followed by assembly using Lasergene software ver. 5.0, has confirmed the presence of serotypes 12 in these isolates. Comparison of full length BTV-12 Seg2 nucleotide sequences (from isolate IND2015/340 - accession no KX905151) and partial 
sequences from the other BTV-12 isolates (not listed here) in MEGA software version 6 (Tamura et al., 2013), showed that these were very closely related to each other ( $99.9 \%$ nt identity) and to another Indian isolate from southern India BTV-12/INDAPADBNMO1/11 (Accession no. KC662613) (99.3\%)(Rao et al., 2013) (Figure 1). Seg-2 of IND2015/340 showed 97.1\% nt sequence identity with the reference strain of BTV-12 from South Africa (Accession no. AJ585133) and Kenya (Accession no. AJ585185), and share 95.8\% to $96.6 \%$ nt sequence identity to strains from Taiwan (Accession nos. GU390659 and AB686216). On the contrary, Seg-2 of IND2015/340 showed greater variation (87.6\% nt identity) from BTV-12 strain from France Guyane (Accession no. KC633278).

Sequencing of partial $\mathrm{N}$ gene amplicons (generated using the primers listed in table 1) from PPRV samples and isolates has confirmed the results of real time RT-PCR assays for the presence of PPRV RNA. Partial N gene based phylogeny (1576 bp of PPRV/IND2015/02 [accession no - KX905152]), revealed that most of the PPRV strains collected from Haryana between 2015 and $2016(n=137)$ grouped together in lineage IV very closely related with other strains from India (IND/Delhi/2016/05 - Accession no. KX033350, IND/TN/GIN/2014/01 Accession no. KT270355 and India/TN/Gingee/2014 - Accession no. KR261605) with 98.4\% to $98.9 \%$ nt identity in $\mathrm{N}$ gene supported by a bootstrap value of $>90 \%$ - (Figure 2 ). However, the $\%$ nt identity in $\mathrm{N}$ gene with the vaccine strain being used in India (Sungri 1996 MSD Accession no. - KJ867542) is 96.8\%. The phylogeny inferred for BTV Seg-2 and PPRV N gene with the distance methods were consistent with those of the character-based analysis.

The findings of this study relating to BT and PPR surveillance in Haryana over a more than one year period (January 2015 - July 2016) have confirmed the widespread distribution of BT and PPRV throughout the province. The concurrent infection of BTV and PPRV has been reported for the first time in Haryana. The concurrent infection of BTV and PPRV has been reported in Haryana. This is the first report of circulation of PPRV lineage IV and bluetongue virus serotype 12 in the state.

\section{Acknowledgements}

The authors would like to acknowledge funding support from BBSRC-DBT (BB/L004690/1; BT/IN/Indo-UK/FADH/46/SM/2013), DBT Bio-CARe grant (BT/Bio-CARe/04/261/2011-12), and Rashtriya Krishi Vikas Yojana (RKVY) from Govt. of India. Sushila Maan is a DBT Bio- 
CARe scientist. The authors would also like to thank all collaborators of BBSRC-DBT project and various staff of Animal Husbandry Department of Haryana for their direct or indirect help.

\section{Conflict of interest}

The authors declare no conflict of interest.

Tables:

Table 1. Details of primers used for amplification of $\mathrm{N}$ gene of Peste-des-petits-ruminants virus (PPRV) and VP2 gene of Bluetongue virus (BTV) for use in RT-PCR assays.

\section{Figure legends}

Figure 1: Neighbour-joining tree showing the relationships between Seg-2 of IND2015/340 with the twenty nine reference strains of different BTV serotypes. The tree was constructed using distance matrices, generated using the p-distance determination algorithm in MEGA 6.0 (500 bootstrap replicates). The bootstrap values are indicated at the evolutionary branching points. The tree based on the character based method (Maximum likelihood) showed very similar topology.

Figure 2: Neighbour-joining tree showing the relationships between $\mathbf{N}$ gene sequence of PPRV/IND2015/338 with the other global strains of Morbiliviruses. The tree was constructed with partial (1576 bp) N gene sequences, using the p-distance determination algorithm in MEGA 6.0 (500 bootstrap replicates). The bootstrap values are indicated at the evolutionary branching points. The tree based on the character based method (Maximum likelihood) showed very similar topology.

\section{References:}

Attoui, H., F. Billoir, J. F. Cantaloube, P. Biagini, P. de Micco and X. de Lamballerie, 2000: Strategies for the sequence determination of viral dsRNA genomes. J Virol Methods, 89, 147-158.

Balamurugan, V., A. Sen, G. Venkatesan, V. Bhanot, V. Yadav, V. Bhanuprakash and R. K. Singh, 2012: Peste des petits ruminants virus detected in tissues from an Asiatic lion (Panthera leo persica) belongs to Asian lineage IV. J Vet Sci, 13, 203-206.

Banyard, A. C., S. Parida, C. Batten, C. Oura, O. Kwiatek and G. Libeau, 2010: Global distribution of peste des petits ruminants virus and prospects for improved diagnosis and control. J Gen Virol, 91, 2885-2897.

Batten, C. A., A. C. Banyard, D. P. King, M. R. Henstock, L. Edwards, A. Sanders, H. Buczkowski, C. C. Oura and T. Barrett, 2011: A real time RT-PCR assay for the specific detection of Peste des petits ruminants virus. J Virol Methods, 171, 401-404. 
Chinnakannan, S. K., S. K. Nanda and M. D. Baron, 2013: Morbillivirus v proteins exhibit multiple mechanisms to block type 1 and type 2 interferon signalling pathways. PLoS One, 8, e57063.

De Nardi, M., S. M. Lamin Saleh, C. Batten, C. Oura, A. Di Nardo and D. Rossi, 2012: First evidence of peste des petits ruminants (PPR) virus circulation in Algeria (Sahrawi territories): outbreak investigation and virus lineage identification. Transbound Emerg Dis, 59, 214-222.

Hofmann, M., C. Griot, V. Chaignat, L. Perler and B. Thur, 2008: [Bluetongue disease reaches Switzerland]. Schweiz Arch Tierheilkd, 150, 49-56.

Jain, N. C., R. Sharma and G. Prasad, 1986: Isolation of bluetongue virus from sheep in India. Vet Rec, 119, 17-18.

Kumar, N., S. Maherchandani, S. K. Kashyap, S. V. Singh, S. Sharma, K. K. Chaubey and H. Ly, 2014: Peste des petits ruminants virus infection of small ruminants: a comprehensive review. Viruses, 6 , 2287-2327.

Kwiatek, O., Y. H. Ali, I. K. Saeed, A. I. Khalafalla, O. I. Mohamed, A. A. Obeida, M. B. Abdelrahman, H. M. Osman, K. M. Taha, Z. Abbas, M. El Harrak, Y. Lhor, A. Diallo, R. Lancelot, E. Albina and G. Libeau, 2011: Asian lineage of peste des petits ruminants virus, Africa. Emerg Infect Dis, 17, 1223-1231.

Lefevre, P. C. and A. Diallo, 1990: Peste des petits ruminants. Rev Sci Tech, 9, 935-981.

Maan, N. S., S. Maan, M. Belaganahalli, G. Pullinger, A. J. Montes, M. R. Gasparini, M. Guimera, K. Nomikou and P. P. Mertens, 2015a: A quantitative real-time reverse transcription PCR (qRT-PCR) assay to detect genome segment 9 of all 26 bluetongue virus serotypes. J Virol Methods, 213, 118-126.

Maan, N. S., S. Maan, M. N. Belaganahalli, E. N. Ostlund, D. J. Johnson, K. Nomikou and P. P. Mertens, 2012: Identification and differentiation of the twenty six bluetongue virus serotypes by RT-PCR amplification of the serotype-specific genome segment 2. PLoS One, 7, e32601.

Maan, S., N. S. Maan, M. N. Belaganahalli, A. C. Potgieter, V. Kumar, K. Batra, I. M. Wright, P. D. Kirkland and P. P. Mertens, 2016: Development and Evaluation of Real Time RT-PCR Assays for Detection and Typing of Bluetongue Virus. PLoS One, 11, e0163014.

Maan, S., N. S. Maan, M. N. Belaganahalli, P. P. Rao, K. P. Singh, D. Hemadri, K. Putty, A. Kumar, K. Batra, Y. Krishnajyothi, B. S. Chandel, G. H. Reddy, K. Nomikou, Y. N. Reddy, H. Attoui, N. R. Hegde and P. P. Mertens, 2015b: Full-Genome Sequencing as a Basis for Molecular Epidemiology Studies of Bluetongue Virus in India. PLoS One, 10, e0131257.

Maan, S., N. S. Maan, K. Nomikou, C. Batten, F. Antony, M. N. Belaganahalli, A. M. Samy, A. A. Reda, S. A. Al-Rashid, M. El Batel, C. A. Oura and P. P. Mertens, 2011: Novel bluetongue virus serotype from kuwait. Emerg Infect Dis, 17, 886-889.

Mahapatra, M., S. Parida, M. D. Baron and T. Barrett, 2006: Matrix protein and glycoproteins F and H of Peste-des-petits-ruminants virus function better as a homologous complex. J Gen Virol, 87, 2021-2029.

Mertens, P. P. C., S. Maan, A. Samuel and H. Attoui, 2005: Orbiviruses, Reoviridae. In: C. M. Fauquet, M.A. Mayo, J. Maniloff, U. Desselberger and L.A. Ball (ed), Virus Taxonomy. Eighth Report of the International Committee on Taxonomy of Viruses, pp. 466-483. Elsevier/Academic Press, London.

Mertens, P. P. C., N. Ross-smith, J. Diprose and H. Attoui, 2009: The structure of bluetongue virus core and proteins. In: P. S. Mellor, M. Baylis and P. P. C. Mertens (eds), Bluetongue, Ist edn., pp. 101125. Elsevier/Academic Press London

Orru, G., M. L. Ferrando, M. Meloni, M. Liciardi, G. Savini and P. De Santis, 2006: Rapid detection and quantitation of Bluetongue virus (BTV) using a Molecular Beacon fluorescent probe assay. I Virol Methods, 137, 34-42. 
Prasad, G., D. Sreenivasulu, K. P. Singh, P. P. C. Mertens and S. Maan, 2009: Bluetongue in the Indian subcontinent. In: P. S. Mellor, M. Baylis and P. P. C. Mertens (eds), Bluetongue, Ist edn., pp. 167196. Elsevier/Academic Press London

Rao, P. P., N. R. Hegde, Y. N. Reddy, Y. Krishnajyothi, Y. V. Reddy, B. Susmitha, S. R. Gollapalli, K. Putty and G. H. Reddy, 2014: Epidemiology of Bluetongue in India. Transbound Emerg Dis.

Rao, P. P., Y. V. Reddy and N. R. Hegde, 2013: Isolation and Complete Genome Sequencing of Bluetongue Virus Serotype 12 from India. Transbound Emerg Dis.

Tamura, K., G. Stecher, D. Peterson, A. Filipski and S. Kumar, 2013: MEGA6: Molecular Evolutionary Genetics Analysis version 6.0. Mol Biol Evol, 30, 2725-2729.

Uppal, P. K. and B. and Vasudevan, 1980: Occurrence of bluetongue in India. Indian. J. Comp. Microbiol. Immunol. Infect. Dis., 1, 18-20.

Zientara, S., C. Sailleau, C. Viarouge, D. Hoper, M. Beer, M. Jenckel, B. Hoffmann, A. Romey, L. BakkaliKassimi, A. Fablet, D. Vitour and E. Breard, 2014: Novel bluetongue virus in goats, corsica, france, 2014. Emerg Infect Dis, 20, 2123-2132. 
Table 1. Details of primers used for amplification of $\mathrm{N}$ gene of Peste-des-petits-ruminants virus (PPRV) and VP2 gene of Bluetongue virus (BTV) for use in RT-PCR assays.

\begin{tabular}{|c|c|c|}
\hline $\begin{array}{l}\text { Oligo Name } \\
\text { eastern (e) or western (w) }\end{array}$ & Oligo Sequence (5'-3') & $\begin{array}{l}\text { Product name } \\
\text { and Size (bp) }\end{array}$ \\
\hline \multicolumn{3}{|c|}{ PPRV N gene specific primers for use in conventional RT-PCR } \\
\hline $\begin{array}{l}\mathrm{PPR} / \mathrm{N} / 51-73 \mathrm{~F} \\
\mathrm{PPR} / \mathrm{N} / 1627-1606 \mathrm{R}\end{array}$ & $\begin{array}{l}\text { CCATGGCTACTCTCCTTAAAAGC } \\
\text { GCCGAGGAGATCCTTGTCGTTG }\end{array}$ & 1576 \\
\hline \multicolumn{3}{|c|}{ BTV-12w VP2 gene specific primers for use in conventional RT-PCR } \\
\hline $\begin{array}{l}\text { BTV }-12 \mathrm{w} / 2 / 1-20 \mathrm{~F} \\
\text { BTV-12w/2/1133-1113R }\end{array}$ & $\begin{array}{l}\text { GTTAAAAGTTGCGAGGATGG } \\
\text { GATYGTTCCTCGTAAGCAGG }\end{array}$ & A: 1133 \\
\hline $\begin{array}{l}\text { BTV-12w/2/896-915F } \\
\text { BTV-12w/2/1576-1555R }\end{array}$ & $\begin{array}{l}\text { CAGATGTGGAATAGTGARGA } \\
\text { ATCRTAATAATACGGCATAACT }\end{array}$ & B: 680 \\
\hline $\begin{array}{l}\text { BTV-12w/2/1404-1442F } \\
\text { BTV-12w/2/2250-2231R }\end{array}$ & $\begin{array}{l}\text { ATGAYACGAAGTATAGAGA } \\
\text { TCTCTRTGTAAATAGCTGAT }\end{array}$ & $\mathrm{C}: 846$ \\
\hline $\begin{array}{l}\text { BTV }-12 \mathrm{w} / 2 / 2105-2123 \mathrm{~F} \\
\text { BTV-12w/2/2904R }\end{array}$ & $\begin{array}{l}\text { GGRCGRTGATGGCGAG } \\
\text { GTAAGTTGAAGCYGCGAGG }\end{array}$ & D: 799 \\
\hline
\end{tabular}




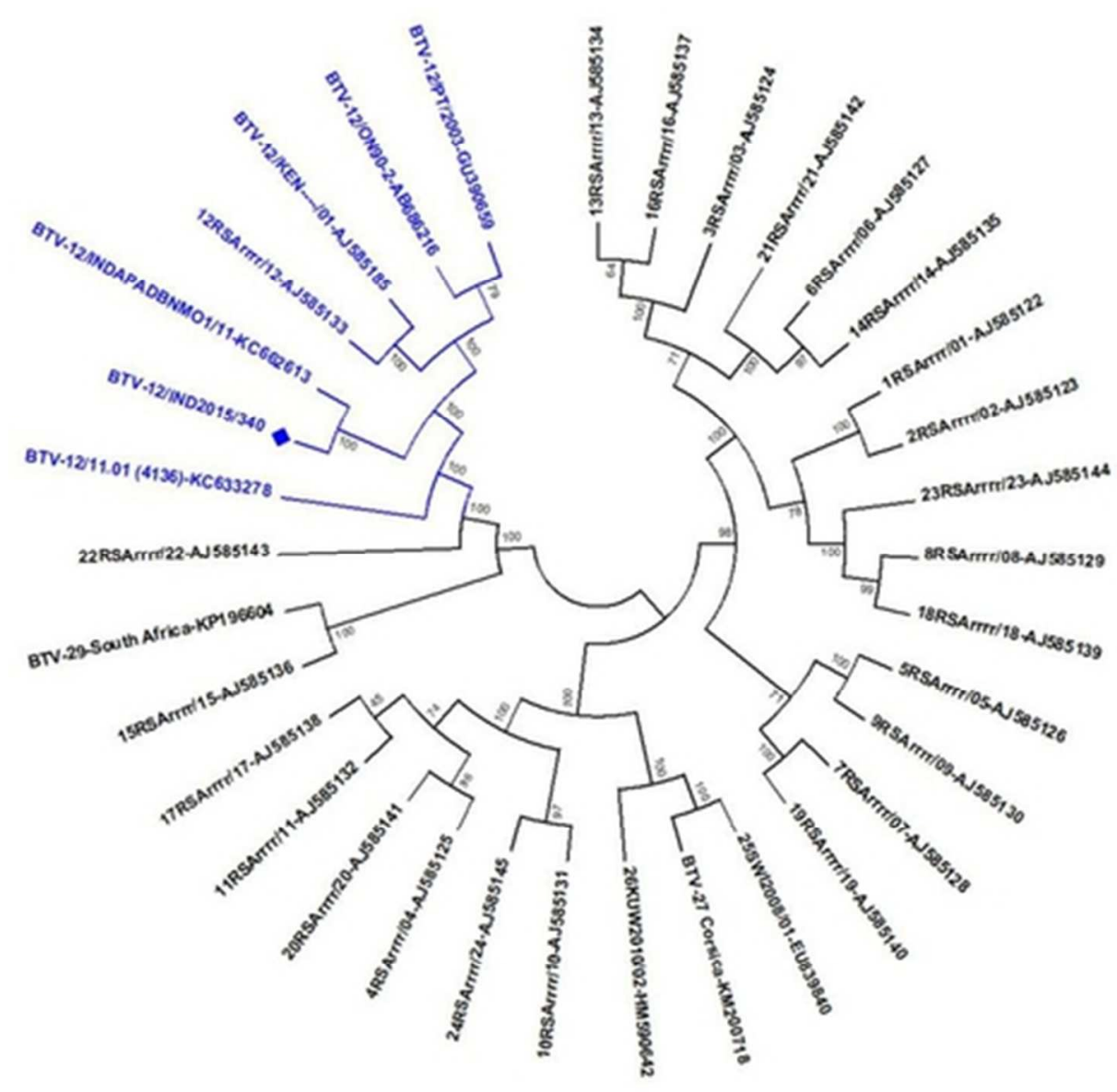

Figure 1: Neighbour-joining tree showing the relationships between Seg-2 of IND2015/340 with the twenty nine reference strains of different BTV serotypes. The tree was constructed using distance matrices, generated using the p-distance determination algorithm in MEGA 6.0 (500 bootstrap replicates). The bootstrap values are indicated at the evolutionary branching points. The tree based on the character based method (Maximum likelihood) showed very similar topology.

\section{$39 \times 38 \mathrm{~mm}(300 \times 300 \mathrm{DPI})$}




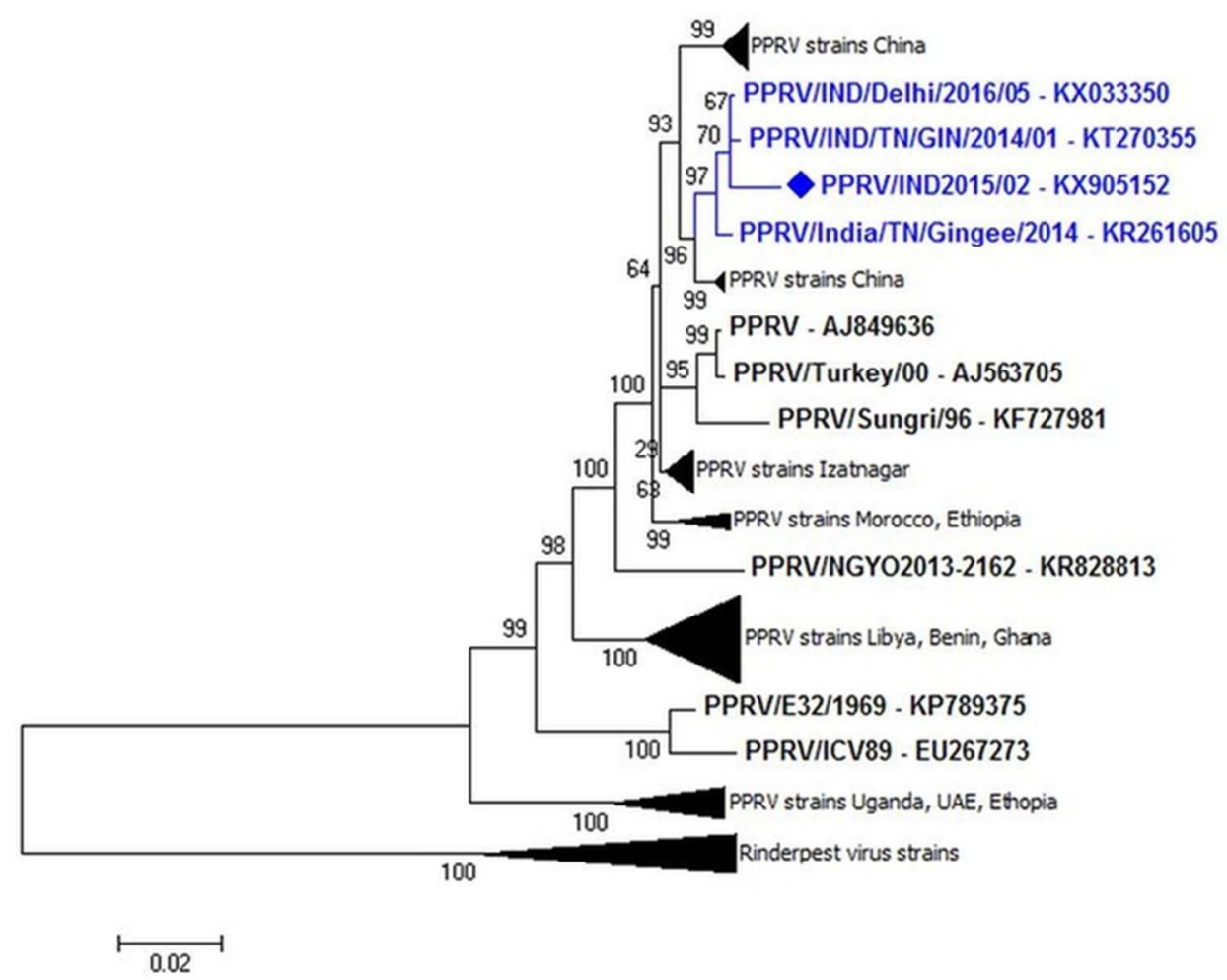

Figure 2: Neighbour-joining tree showing the relationships between $\mathrm{N}$ gene sequence of PPRV/IND2015/338 with the other global strains of Morbiliviruses. The tree was constructed with partial (1576 bp) N gene sequences, using the p-distance determination algorithm in MEGA 6.0 (500 bootstrap replicates). The bootstrap values are indicated at the evolutionary branching points. The tree based on the character based method (Maximum likelihood) showed very similar topology.

$62 \times 47 \mathrm{~mm}(300 \times 300 \mathrm{DPI})$ 